\title{
Review of Data Mining and Data Warehousing Implementation in E-Governance
}

\author{
Dr Rohini Jha \\ Assistant Professor, Department of Management \\ BIT Mesra, Ranchi
}

\begin{abstract}
Nowadays, the role of information and communication technology plays an important part in the Indian government administration. Because of the government, it has to handle a large amount of citizen's data and recent increases of online accessibility. However, due to the lack of unstructured knowledge, it develops complexity while analyzing the data. The issues in the e-governance can be solved using efficient data mining methods. In this review, various researches on the works in the data mining as well as data warehouse in e-governance are investigated and compared. The significances and issues in the e-governance are discussed for the future enhancement. Consequently, the illiteracy rate and literacy rate after the development of e-governance in India is measured. Moreover, the few performance evaluations of e-governance application are an investigation for the validation of the efficiency. The meta-analysis of execution has been done in this review.
\end{abstract}

Keywords: E-Governance, Data Mining, Education, Data Warehousing, Meta-Analysis, Performance Evaluation.

\section{INTRODUCTION}

India is a massive self-governing country having multilevel governmental establishments from the level of national to the state and district level of blocks (Govinda \& Bandyopadhyay, 2006). Numerous quantities of data are created and distributed using various administration departments at numerous stages of government (Kalsi et al., 2009). Therefore, all the information distributed from the various administrations is integrated significantly, and thus the entire department of the government can act under an individual regulation authority without replication of work (Sivani, 2020). The central general data warehouse model is significant. The model has been vertical and horizontal based interconnections that have a lower and higher level of accessibility. The lower stages of departments have restricted convenience and the higher level has the rights of fully controlled convenience (Shah, 2007). Consequently, the variety of land condition is included in India. This variation is spread across depends upon the people's language, economic state, culture along with geography of the place. In India, the majority of people live in a place beneath the negligible socio-economic standards.

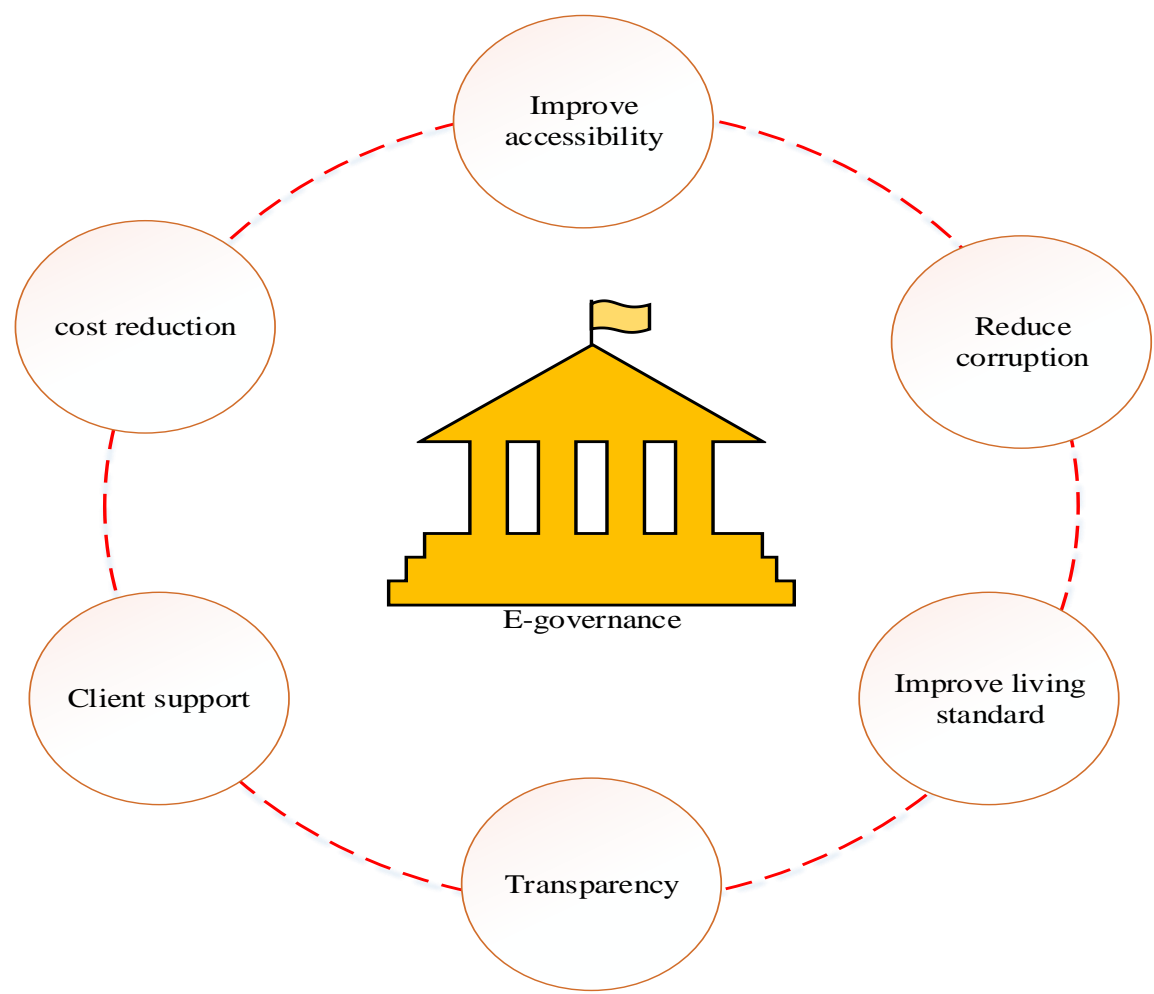

Fig.1:- E-governance creativities in India 
In Indian society, the minimal standard has not only the disadvantages of fundamental requirements yet also the absence of skills and primary education. This much of people have some poorer social advancement like education, health, drinking water availability and hygiene (Haque, 2002). Hence, the suitable level of these people's life quality is diminished. Therefore, these people are intimidating, which is tolerate and enhancing the living standard of people by means of developing and advanced task (Gupta, 2012). For this reason, the e-governance system is identified by the Indian government for the minimal standard life enhancement in terms of the countries development as well as providing opportunities to these kinds of sections in society. Consequently, this system provides a section of the public with a reasonable contact with economic chances (Mazzarella, 2006). India experience the value of cost reduction, accessibility enhancing and corruption diminishing. This is successfully achieved by the creativities of e-governance, which is illustrated in Fig.1. The infrastructure advancement is significant in India because India has a high number of global population. If the literacy is enhanced, these advantages can be obtain from egovernance (Singh et al., 2010). The administration method accomplishes and distributes the data with the inside and the outside users using e-governance. Consequently, mobile computing, wide area network and the internet of information and communication methodologies are connected and changing the associations with the industries, people and between numerous supports of government (Thomas, 2009).

The Citizen Centric e-Governance necessary in India has been deliberated by (Chakravarthy, 2014). Moreover, maintaining the culture, dispensation and the data saving development via an electrical method and the data usage for decision making is discussed by this author. In numerous opportunities, the Indian government has specified its pledge to provide a significant and translucent administration to all layers of civilization (Gupta et al., 2017). Nowadays, e-governance plays a significant part in the role of authority of countries and managerial improvement program. The main aim of the Indian government is to provide the authority that is simply agreed and reasonable to the citizens (Mukherjee, 2018). Consequently, citizen-centric authority and the transparent government enclosed its services and esteem each one as single by giving that modified services.

\section{E-GOVERNMENT PARTICIPANTS}

In any country, the e-government execution should occupy energetic participation and influence numerous participants in the entire function. Some of the fundamental significant participants are summarized below reported by (Kiflie Worku, 2019).

Government Departments: In the country, each level of public segment association sections should guarantee a faultless backend incorporation of systems discussed by (Saxena \&Chandra, 2005). Moreover, the perfect changes and procedures maintain the smoothness of government to an electronic condition. In general, the e-awareness among community segment employees also gives their benefits to squeeze alteration into the main role (Madon, 2004). The integration of public sector agencies has a significant part in the fact that their easily regulated services, hypothetically diminishing monotony along with the exhaustion of provision of citizens, are very important.

Political leaders: For the effective operation of egovernment, standing is not sufficient in the well-developed e-government (Allen, 2001). The governmental leadership inside the country should develop as enthusiastic or as aware.

Legislative Forms: And e-government scheme is successful if the preparation and function of well-developed information technology laws as well as policies is mandatory (Pappel et al., 2019).

Private Segments: In e-government creativities, the private segment can be a foundation and via global expertise and advanced methods usage provide an assessment of the creativities of e-government. Besides, transparency, responsibility and the efficiency enhancement of the government are the main advantages of the private sectors (Coe, 2001).

Citizens: In the whole process, citizens are the foremost beneficiaries. They wait for a rapid and easily delivery of online data and services for the government. Furthermore, this plays an essential role significantly in the progression of policy developing by means of articulating their views and opinion via digitally studied (Riley \& Gilbert, 2003).

Non-Governmental and International Organizations: The e-government creativities projects are effectively promoted by the instigators and essential organizers of NonGovernmental Organizations (NGOs) and international organizations (Liu \& Feng , 2017). Consequently, these organizations can develop the awareness between the people in the society and directing research in this field also plays an essential part. The e-government stands are previously proven the finest accomplishes between the countries while exchanging.

\section{BENEFITS OF E-GOVERNANCE}

On the word of the World Bank, there are some following advantages in e-governance. The e-governance importantly shortens the information growth process in businesses and citizens (Dash \& Pani, 2016). In any governmental department, information gathers from authorizes people this approach plays a main role and provides the decision making of the complication stage. The involvement at all stages of governance confirming the superior of the citizen improves the e-governance of equality (Gupta et al., 2018). Moreover, the computerization of facilities is provided by e-governance to the public for performing that information for each operation of public welfare system, which is applicable to all the citizens in the society and tends to corruption elimination. Therefore, in 
this way of government process transformation tends to perform the government as transparent and this reduces the corruption investigated by (Botchway et al., 2016). Furthermore, if people do their works via online then the travelling to the particular office is avoided and it helps the citizens economically by the suitable execution of egovernance.

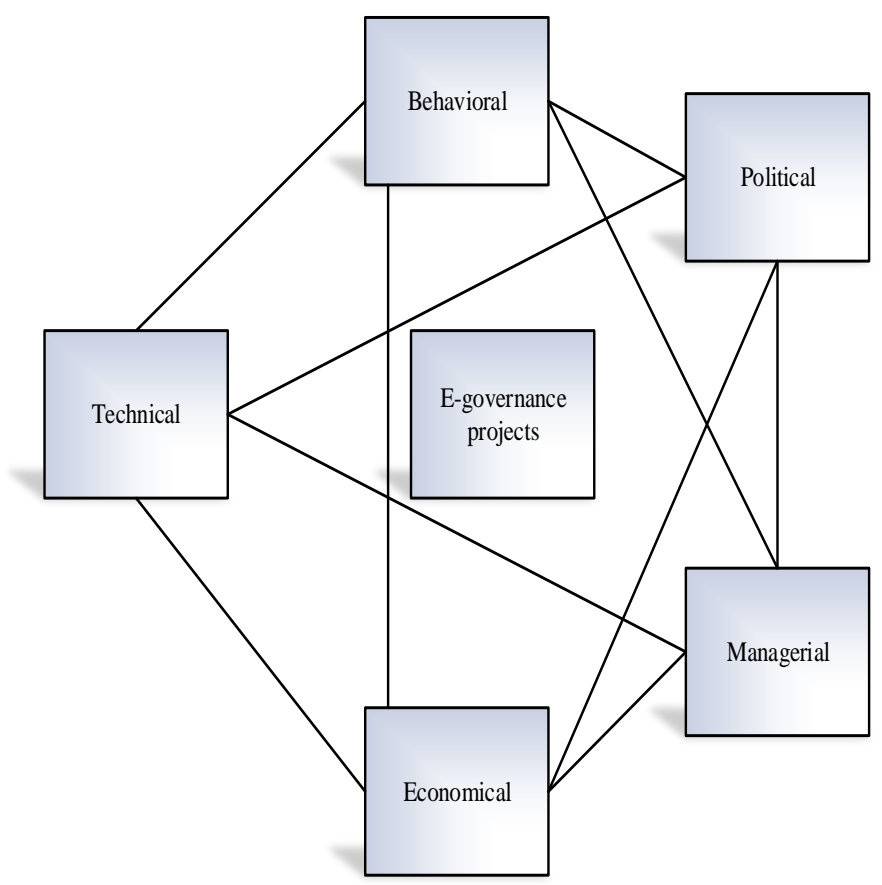

Fig.3:- The significance of e-governance in its projects

The effective execution of e-governance creative provides the finest distribution of facilities to the community and enhanced the communications with industry as well as business, finest management, revenue development, supreme accessibility, empowerment of citizens via the information access, cost minimizations, etc., (Suri, 2017). Therefore, the e-governance developments bring governments nearer to the citizens of the country. Nowadays, the citizens can be able to touch with the government offices in a convenient way. Currently, the citizens and the service centers are placed nearer. The service centers consist of service centers nearer to the citizens, unattended booths in the administration support or private computer in the home/office. Moreover, in the business information contact the creativities of e-governance might be significant for them in a business connection. Formerly, (Gupta et al., 2008) studied the National eGovernance Plan (NeGP) is created by the government, which enclosed 8 provision mechanisms to be executed by the level of governments such as central, state and native along with twenty seven mission mode projects (MMPs). Moreover, these schemes include the development of customs, land records, state level of district policies, central level of passports policies, income tax and local level of municipalities as well as panchayat's polices.

\section{CHALLENGES IN E-GOVERNANCE}

There is a lot of operation taken to investigate digitally produced data from the e-governance. However, it has numerous problems that will happen in the management of data and the analysis methods of data (Giri et al., 2018). These issues must be investigated by various researches. There are the major problems in remote area of Indian country, due to the lack of information and communication, lack of human expert resources and lack of e-sources of data. Therefore, these demerits limited the development of e-governance facilities to seventy percentages of Indian inhabitants who survive in the remote areas. Consequently, the major challenges investigated by (Nagaraja, 2016) which includes in the e-governance are summarized below;

1. Sustainability, Integration and Interaction.

2. Infrastructure, technical separation and Speed.

3. Native gratified based on native language.

4. Human Capacities Structure, Connectivity and ECommerce.

5. Technical and security variations.

6. Progression and administrative inactivity.

7. Valuation of native requirements and modifying egovernance explanations to encounter those requirements.

The electronic governance execution using the data mining approaches has certain key issues, which are described as follows: Self-motivated environment of a database, large number of databases developing at an exponentially rapid speed, attributes selection and hidden datasets. Furthermore, the lack of universal or global unique values along with the misplaced characteristics in the database (Oliveira et al., 2020). Lack of suitable E-sources in electronic data, such as similar, spotless, worldwide and operative data analytic methods are the main limitation and problem (Misuraca et al, 2014). Moreover, the analytics of big data and the data mining methods may provide the solution for the challenges and enhance the execution of egovernance performances. The analytics of big data may give the prospects in business analytics development to encourage the finest utilization along with the personalization enhancement of the services in egovernances (Dawes, 2008). This also reports the challenges of data management.

\section{SOLUTION FORESEEN}

The e-governance has some major challenges. Yet, the important condition is whether significant data on the exact time with supreme security and precision is significant. Then, the citizens should obey the conditions, regulations along with the advanced methods to provide the appropriate database for creating the decision (Abreu et al., 2018). Normally, the databases and files are considered for the data of decision-making storage. However, the large quantity of the data is difficult to process for this reason the data mining approach plays a very positive field (Sangeetha \& Manjunatha, 2016). The data mining approach is a function of taking obtainable the finest data by means of rules and 
configurations from the large set of databases (Khot et al, 2017). The data mining techniques may include classification tree, incorporation rules sequential patterns etc., (Navdeep, 2016). Therefore, it is also mentioned as information detection or statistics. Furthermore, the data warehouse also helps by the dissimilar kinds of analysis, which is enclosing the question explanation on a huge amount of data which is necessary for a wide range of examining (Verma et al, 2015). However, in the last eras both the data mining and data warehousing of correlated methodologies played a significant role in the e-government growth boosting.

\section{DATA WAREHOUSE APPROACH}

The data removed from the working structure and developed as an obtainable as antique portraits for ad-hoc investigations and programmed broadcasting. The data warehouse mainly takes attention on data storage (Alkraiji, 2015 \& 2020). Moreover, it can be considered as the data warehouse which is mainly utilized to analyze and recover the data along with to Extract Transform as well as Load (ETL) data. Also, the dictionary of data is maintained (Coman, 2009). In organization requirement, data warehousing has an important role due to its characteristics. Furthermore, it gives essential merits at various level of combination like data analysis, incorporated and limited reporting, unwavering combined of data (Wadhwa, 2020). In the decision creation of data, various amount of information is taken by the governments. Therefore, the data of citizens and land are incorporated in a data warehouse constructed for e-governance. While the better polices are developed by the government, the suitable data provides the finest relief to the supreme business level and other public sectors (Alhawawsha, 2020). The basic accountability of government is to vary all the data correlated to the business and people in an apparent way. The configuration of data ware house in e-governance is shown in Fig.2. Furthermore, the advantages of data warehouse are summarized as follows: Data warehouse has satisfactory performance to be accurate to utilize the influence of different good schemes all over the state (Panganiban, 2019). Data warehouse is mainly played in the area of urban and rural advancement, cropping pattern in agricultural and other investigation (Sidi et al., 2016). The data from the agriculture is gathered and based on the variation of weather and climatic conditions, the data has been analyzed that can affect the crop production. However, this method is easily forecasting the features (Böhnlein et al., 2000). Moreover, the computing techniques are developed which helps the business development and computer systems. Data reliability is enhanced and the citizens in the state can be able to contact the development of state government policies (Kern et al., 2020). The decision can be taken simply by comprehensible and comprehensive material without the essential to use erudite tools. The most of the native governance functions are mainly based on the participants and sets of various native governments in the globe.

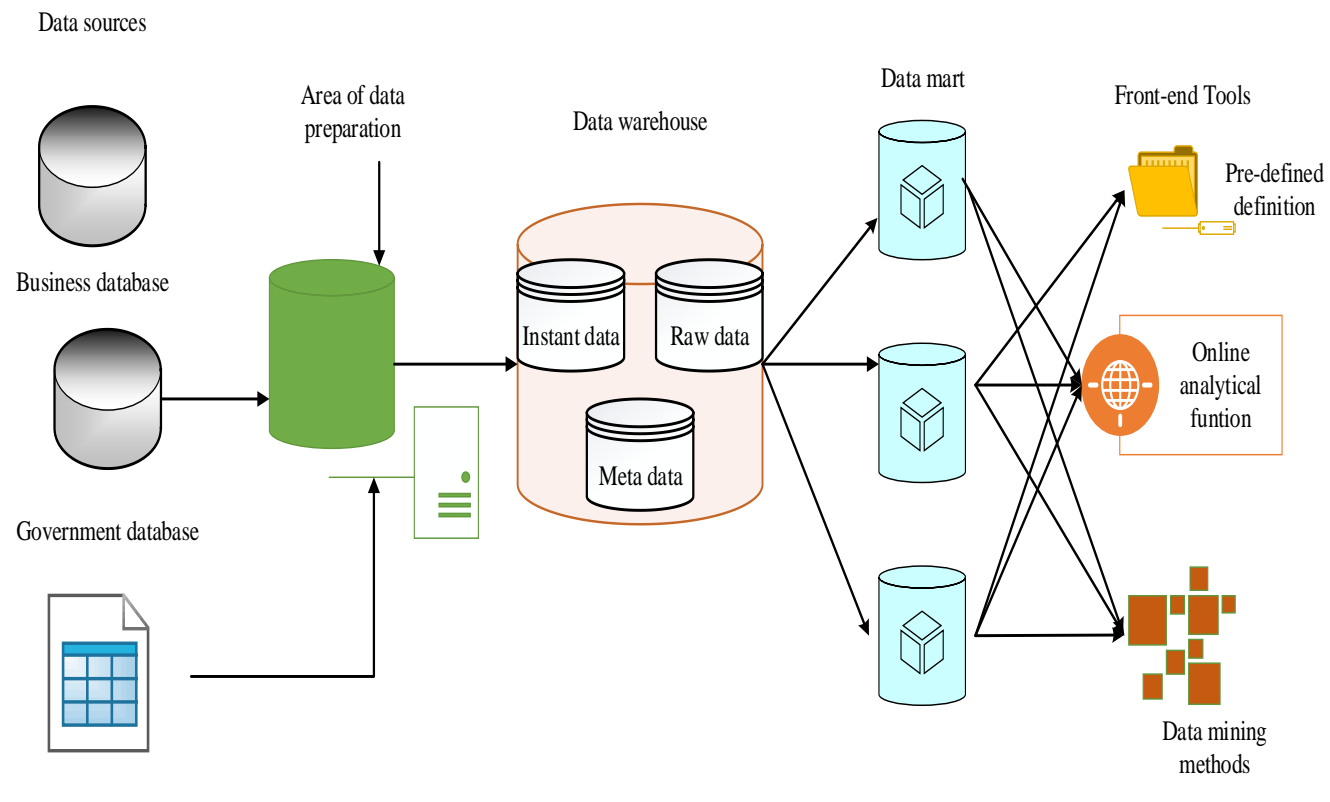

Documents

Fig.2:- The configuration of data ware house in e-governance

Therefore, many researchers have developed various techniques for the data warehouse design performance in an automatic way that can provide a centralized decision in an accurate assessment. For this reason, (Chakiri, 2020) developed a hybrid method for the extraction of the data warehouse. The source based scheme and the extraction based scheme are combined in the data ware house approach. However, this method has some limitation such as the accessing of data in the administration and the regulatory characteristics of the developing. The developing is complex and the entire computerization data warehouse design is complex. In any country, the driving strength of the data is the main part in the economy growth. Nevertheless, the large amount of data handling is a major problem in the data warehouse. Traditionally, machine learning, artificial intelligence based techniques are utilized in the computation 
of big data. But, the data needs to be a raw form for the data engineers. To overcome such problems, a new data warehouse method is developed which is mentioned as Data Lake introduced by (Arvind Panwar \& Vishal Bhatnagar, 2020). The main aim of this method is to investigate the data lake knowledge form the viewpoint of operators and the viewpoint of knowledge. (Shubhangi Tirpude, 2020) The Kmeans clustering, RStudio, and ARIMA model for forecasting depends upon the ecological characters of India such as water quality, tree cover, quality of air and forest. The data warehouse in the business development from the data source is analyzed using the decision support system which is discussed by (Jayashree \& Priya, 2020). The private of a governmental educational organization has been improved by the execution of data warehouse utilization in education. (Wawan Solihin, 2020) developed a transforming building data into a simplified schema (BIMRLSS) method for enhancing the yield of the AECO manufacturing. However, this method is only applicable to the fewer barriers. In data warehouse, the quality of the data problem is reduced using chance-constrained programming based on modified Artificial Bee Colony algorithm which is developed by (Qi Liu. 2019). Here, the data ware house approach is utilized in the healthcare administration. In recent times, the various smart society and smart city projects have utilized based on the Internet of Things (IoT) along with the big data. (Nan Zhanga, 2020) developed a synergetic model and Qualitative Comparative Analysis (QCA) for the business and information technologies. The summary of data warehouse execution on e-governance are detailed in Table. 1

\begin{tabular}{|c|c|c|}
\hline Author, year & Area & Remark \\
\hline Chakiri, 2020 & Public administration & $\begin{array}{c}\text { Hybrid method for the extraction scheme in data } \\
\text { warehouse }\end{array}$ \\
\hline $\begin{array}{c}\text { Arvind Panwar and } \\
\text { Vishal Bhatnagar, 2020 }\end{array}$ & Data engineering & $\begin{array}{c}\text { A new data warehouse method is developed which is } \\
\text { mentioned as Data Lake }\end{array}$ \\
\hline Shubhangi Tirpude, 2020 & Indian ecological & K-means clustering, RStudio, and ARIMA model \\
\hline Jayashree and Priya, 2020 & Education & The decision support system \\
\hline Wawan Solihin, 2020 & healthcare & A simplified schema (BIMRLSS) method \\
\hline Nan Zhanga, 2020 & business and information technologies & $\begin{array}{c}\text { Chance-constrained programming based modified } \\
\text { Artificial Bee Colony algorithm }\end{array}$ \\
\hline
\end{tabular}

Table.1:- summary of data warehouse execution on e-governance

\section{DATA MINING APPROACHES}

In e-governance, both data mining method and data warehousing are a significant method for active data management and model detection in the current methodologies. From that, data mining is an essential methodology. This method can provide the hypothesis answers which were taken a very long time to resolve (Chamikara , 2020). The hidden designs are estimated by the generated database and forecast by the experts due to the falsehoods of external prospects. Moreover, data mining is a precise, cooperative and iterative procedure. By means of advanced modeling and analytical methods, the crucial problem can be solved from the depth of the issues. The data mining method contains some important steps such as the definition of a crucial problem, investigation of data, preparation of data, method modeling, and performance evaluation along with the method implementation. The process of data mining is illustrated in Fig. 3

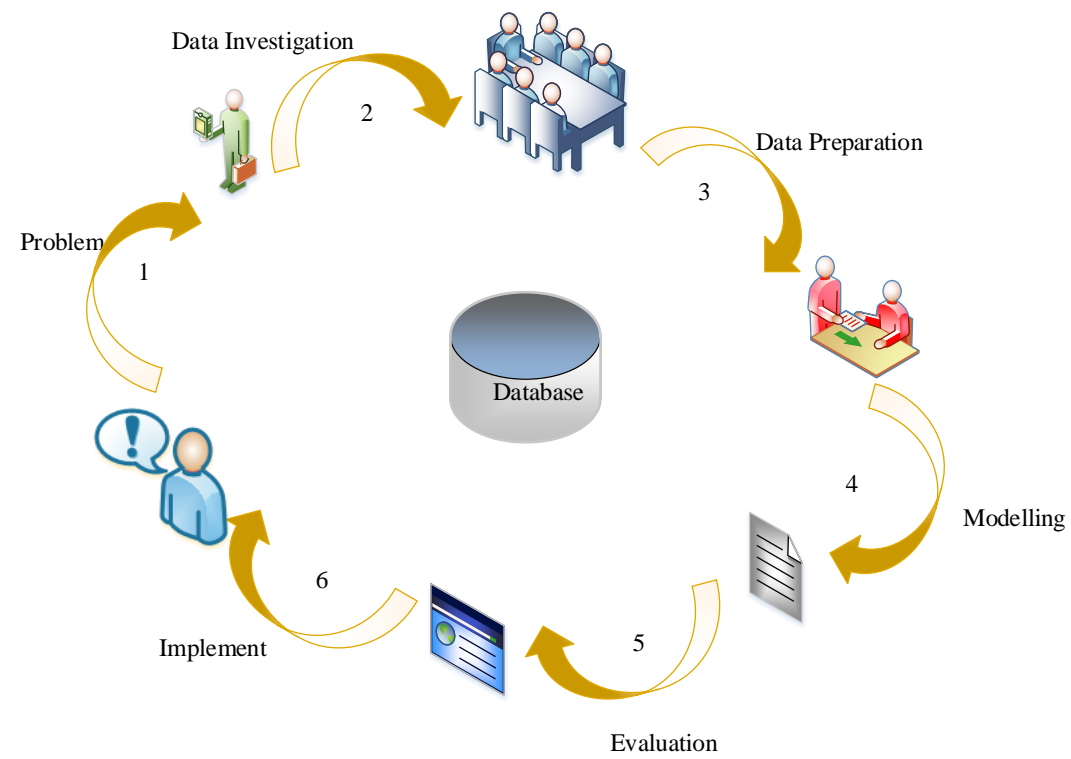

Fig.3:- Process of data mining method in e-governance 
Initially, the problem of the crucial state is required to identify. For this, the objectives of the project and the business necessaries perception are composed together, which is nearly placed by the experts of data mining. In the next step, the data are collected, represented, and determined for the data investigation. Consequently, the quality of the data issues are recognized. The very next stage, the exact raw data set is necessary to convert in to the final data set for the subsequent process. Moreover, in this stage, characteristics chosen, table, variations and dusting of data for exhibiting platforms are considered. The fourth stage is the important prospect which is examining the modeling of all methods in a high quality. Consequently, the developed model is investigated by the experts. The objective of business and the problem in the business are examined by the developed models. Finally, the finest outcome of the data mining is illustrates. The monotonous function of data mining is utilized for the outcomes of mining methods by the experts. The process of data mining is repeated until the finest solution is achieved. Nowadays, the completion is increased for the success achievement between the businesses. Hence, a large quantity of information or data is required to be collected for the business (Shukla et al., 2020). In e-governance, the finest decision making data mining is an essential part. The data mining approaches are mainly utilized in the prediction and prognostic strategies objectives. Moreover, it encloses the data incorporation, better data chosen along the expressive data conversion.

Consequently, the data mining method is mainly utilized in various areas due to significant importance such as enhancing the company revenue while purchased by the customers, fraud identification, upcoming enhancement, analysis of market carrier and others. The advantage of data mining is summarized as follows: In the large amount of data analysis the skill detection function, the data mining is an essential method. In financial administrations, the credit report and loan information data can be provided by the data mining method. In engineering manufacturing operation, the component fault and the finest regulation parameters are also performed by data mining methods. For the financial transaction records in the government offices data mining is utilized for excavating as well as analyzing. In criminal investigation based on the law, this method recognizes the criminals in terms of kind of crime, behavior features, criminal prospects, location and habit. The data mining helps the researchers in terms of data analysis and this will tends to minimize the time consumption of woks. Therefore, they can take consideration of other works.

Different countries executed the e-governance to empower the economy and their objectives. The interaction between the government and people is mainly done by the social media. (Alkashri, 2020) introduced a Linear Support Vector Machine (LSVM), decision tree, navies, islands, Knearest neighbor and a Random Forest based machine learning technique for the analysis of Twitter comment from the Dubai government. (Nur Siyam, 2020) projected numerous machine learning methods for Adaboost and Random Forest for citizen commitment to the tweets of government. The various states of India's financial position is investigated by (Kondeti et al., 2019) using neural network, Naive Bayes, classification and regression method. The confusion matrix is developed for the performance estimation. (Wang et al., 2019) developed a Knowledge Discovery in Databases (KDD) method for the data analysis of National Health Insurance Administration (NHIA) call center in Taiwan. The rapid decision helps to provide the public requirements in the finest quality. In a dissimilar application, the watermarking is applied for the content confirmation and copyright security. Therefore, (Singh \& Chandan Kumar, 2020) developed the combination of encryption along with compression depend on watermarking approach. Here, redundant discrete wavelet transform (RDWT) method is developed for the host image conversion and singular value decomposition (SVD) is applied in its coefficients. The PAN card validation is taken as the application in this research. The watermark of the picture is encrypted using the 2D based hyperchaotic encryption. (Almushayt, 2019) proposed the AI methodologies for solving the issues of e-governance structure. The e-government services are mainly automated using deep learning approaches. Moreover, the smart e-government environment based structure is developed based on the execution of AI. The cost and processing time are minimized and the satisfaction of the citizens is enhanced. The difficulties in the IoT based smart meter methodologies are investigated and discussed using the Unified Theory of Acceptance and Use of Technology (UTAUT2) by (Alkawsi et al ., 2020). The data from the two towns in Malaysia are taken and the input is provided to the neural network approach to forecast the suitable characteristics. Moreover, the Structural Equation Modelling (SEM) analysis is investigated. However, this method created inferences for users and policy developers.

(Hasi \& Vanthienen, 2020) projected the Decision model and the notation (DMN) of guidelines for the connected area like information technique engineering, decision table modeling along with software engineering. Moreover, the suggested modeling strategies are developed for the real time sceneries. In this research, the tax management e-service of the government in Belgium is considered. The avola tool is used for the modeling of this execution. In the country, both government to citizens (G2C) and government to government $(\mathrm{G} 2 \mathrm{G})$ role has been more important. Therefore, (Pabitrananda \& Subhashree, 2020) projected a decision making approach for the land record e-governance project at odisha. Consequently, (Pabitrananda \& Subhashree, 2019) investigated the AI, data mining and machine learning for increasing the efficiency of e-governance. The e-mutation method is developed for the enhancement of delivery service by means of ICT with the Record of Rights (RoR) of online updating. (Desai, 2019) introduced the ANN method for the registration of birth in the e-governance data source. The Microsoft Analysis Service was considered for the real time execution and the Microsoft Neural Network based data mining method is developed for the correlation of simulation outcomes. (Malhotra et al., 2019) developed a machine learning algorithm for cyber-attacks happening in e-governance. This 
provides transparency, supreme accountability and confidentiality to the government.

\begin{tabular}{|c|c|c|c|c|}
\hline Authors \&years & Research Area & method & $\begin{array}{c}\text { Practical } \\
\text { Implementation? }\end{array}$ & limitation \\
\hline Alkashri, 2020 & Social media & $\begin{array}{l}\text { machine learning } \\
\text { methods }\end{array}$ & No & $\begin{array}{l}\text { All the methods can't perform } \\
\text { well is single system. }\end{array}$ \\
\hline Nur Siyam, 2020 & Social media & $\begin{array}{l}\text { machine learning } \\
\text { methods }\end{array}$ & No & $\begin{array}{l}\text { The link between the } \\
\text { government and the community } \\
\text { is reduced. }\end{array}$ \\
\hline Kondeti et al., 2019 & $\begin{array}{l}\text { Socio financial } \\
\text { position }\end{array}$ & $\begin{array}{c}\text { Neural network, Naive } \\
\text { Bayes, classification, } \\
\text { regression }\end{array}$ & No & $\begin{array}{l}\text { Incremental learning is absent } \\
\text { in this method. }\end{array}$ \\
\hline Wang et al., 2019 & NHIA call center & KDD & yes & $\begin{array}{l}\text { The dissimilar data cannot be } \\
\text { performed well. }\end{array}$ \\
\hline $\begin{array}{l}\text { Singh and Chandan } \\
\text { Kumar, } 2020\end{array}$ & $\begin{array}{l}\text { Content confirmation } \\
\text { and copyright security. }\end{array}$ & RDWT, SVD & Yes & $\begin{array}{l}\text { Lacking of rapid solution } \\
\text { affects the overall performance }\end{array}$ \\
\hline Al-mushayt, 2019 & e-government services & $\begin{array}{l}\text { AI, deep learning } \\
\text { approaches }\end{array}$ & Yes & $\begin{array}{l}\text { Quality of the system is } \\
\text { diminished }\end{array}$ \\
\hline Alkawsi et al ., 2020 & smart meter & neural network & Yes & $\begin{array}{l}\text { Inferences for users and policy } \\
\text { developers. }\end{array}$ \\
\hline $\begin{array}{c}\text { Hasi and } \\
\text { Vanthienen, } 2020 \\
\end{array}$ & $\begin{array}{l}\text { tax management e- } \\
\text { service }\end{array}$ & $\mathrm{DMN}$ & Yes & Execution time is high \\
\hline $\begin{array}{l}\text { Pabitrananda and } \\
\text { Subhashree, } 2020\end{array}$ & land record & AI & Yes & Cost of this approach is more \\
\hline Desai, 2019 & $\begin{array}{l}\text { registration of birth in } \\
\text { the e-governance }\end{array}$ & ANN & Yes & $\begin{array}{l}\text { Need to improve more for the } \\
\text { analysis }\end{array}$ \\
\hline Malhotra et al., 2019 & cyber-attacks & $\begin{array}{l}\text { machine learning } \\
\text { algorithm }\end{array}$ & No & $\begin{array}{l}\text { Performance is affected by such } \\
\text { disturbances. }\end{array}$ \\
\hline
\end{tabular}

Table 2:- Summary of related work on the data mining execution of e-governance

\section{EFFECT AND PART OF DATA MINING AND} DATA WAREHOUSING IN E-GOVERNANCE

The aspiration of the e-governance is to authorize people to contact the practice of material. The large quantities of data are necessary in the government. For creating the finest decision, the data has been provided in an effective way (Kum, 2009). The governance issues and administration issues in the society can be resolved using data mining methods. For instance, in India at Karnataka, the government has developed a project named as bhoomi which is constructed as e-governance with the use of data mining method studied by (Hanumanthappa et al., 2010). This project helps to regulate and update the records of agricultural land. The data of weather variation and climatic data are taken from the agricultural data for the analysis that can affect the crop production. Furthermore, the weather and climate variation forecasting can help to enhance the agricultural outcomes. The data mining method and data warehousing approaches are mainly utilized in various fields such as health, commerce and trade, revenue, agriculture, tourism, education, planning and others (Kim, 2014). In India, the illiteracy is a complex problem due to the community and economic separation of the country. Moreover, the illiteracy problem tends to be caused by technological issues, gender judgment, and economic differences along with the caste judgments. Large numbers of adults are illiterate in India, which can cause some serious issues (Lee, 2020). The literacy level in India is diminished because of the high number of females who are illiterate. The literacy rate is varied between the male and female genders. The literacy rate of male is as high as $82.14 \%$ and the literacy rate of female is reduced to $65.4 \%$. Over $37 \%$ of the entire world's adults are illiterate, as shown in Fig.4

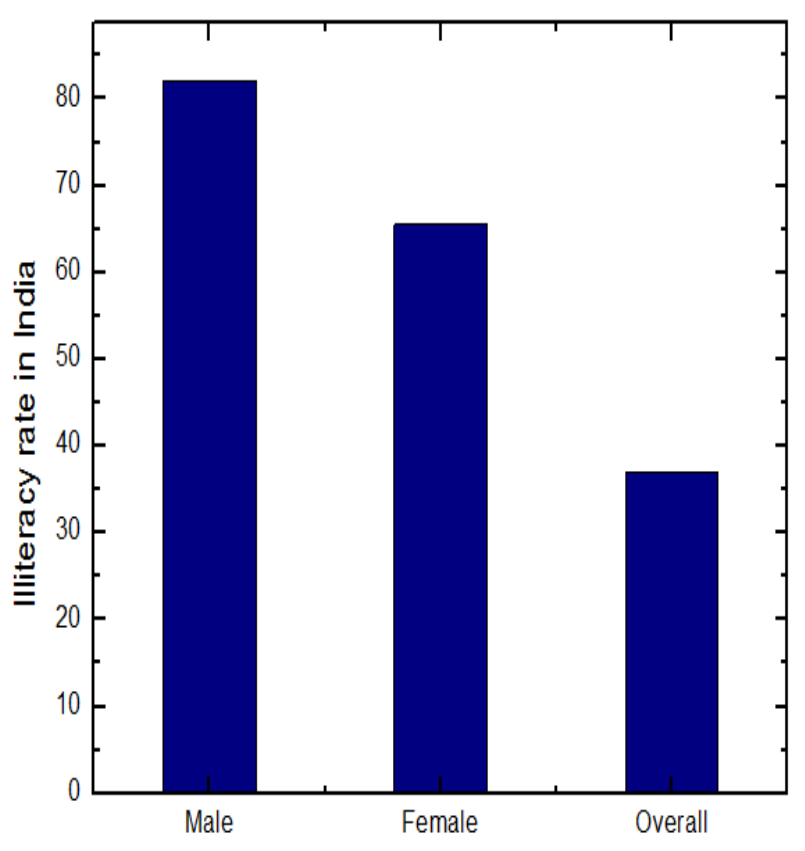

Fig.4:- Illiteracy rate in India 
In academic involvement, the data mining is an important tool. Significant data is extracted by means of data mining methods. The country is said to be successful while the education level is the foremost part. In the learning environment, the data mining is referred to as the education data mining method. The development and improvement of the country requires the finest education. In the educational system, data mining has an important part in the emotional and computational method, which is considered as the developing research field. Moreover, this research methodology helps to know the learning capability of students. Therefore, this new computer assisted intelligent learning system gathers student data and analyzes the data about the students learning capacity investigated by (Khan et al ., 2020). The learning behavior students forecasting help to create motivation, attitudes and more knowledge to students. The data mining technique is a dominant method of other new technologies due to its supreme information structure. The advanced learning institution is mainly utilized the data mining approaches. In e-governance, the data mining assist the educational system and it brings overriding managerial suspensions, responsibility, clarity and improves the weakness of education level in schools such as technical as well as supreme. The growth of Indian literacy is very slow till the year of 1947 . However, the rate of literacy level is improved from the year of 1991 to 2000. The latest information of the literacy rate of India is $74.37 \%$. The past over periods significantly improved the literacy level of India and $65.9 \%$ of women are literate. The literacy rate in India is illustrated in Fig.5..

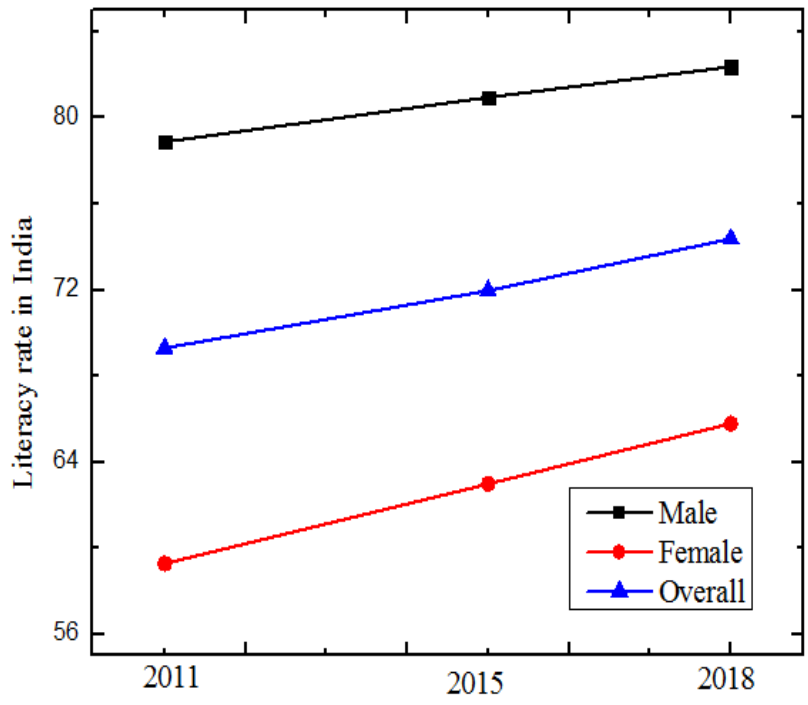

Fig.5:- Literacy rate of India over 2018

Consequently, various types of significant projects have been done by the NeGP organizations during endorsing excellence and cooperative education. The NeGP projects such as National Knowledge of Networks, Structure in terms of ICT @ Schools and MMPs (Chauhan, 2009). Moreover, with the use of EduSAT the teachers can easily teach online. Nevertheless, the use of novel approaches in learning empower the teaching and training of students.

\section{PERFORMANCE EVALUATION}

Various statistical and methods have been investigated for the development of e-governance. Here, some of the methods are compared for verifying the performance in egovernance. The function of data mining methods is validated in terms of accuracy, precision, f-measure and recall. The various applications have been considered in the comparison such as social media (Alkashri, 2020), education (Khan et al., 2020), and socio financial position (Kondeti et al., 2019) and so on.

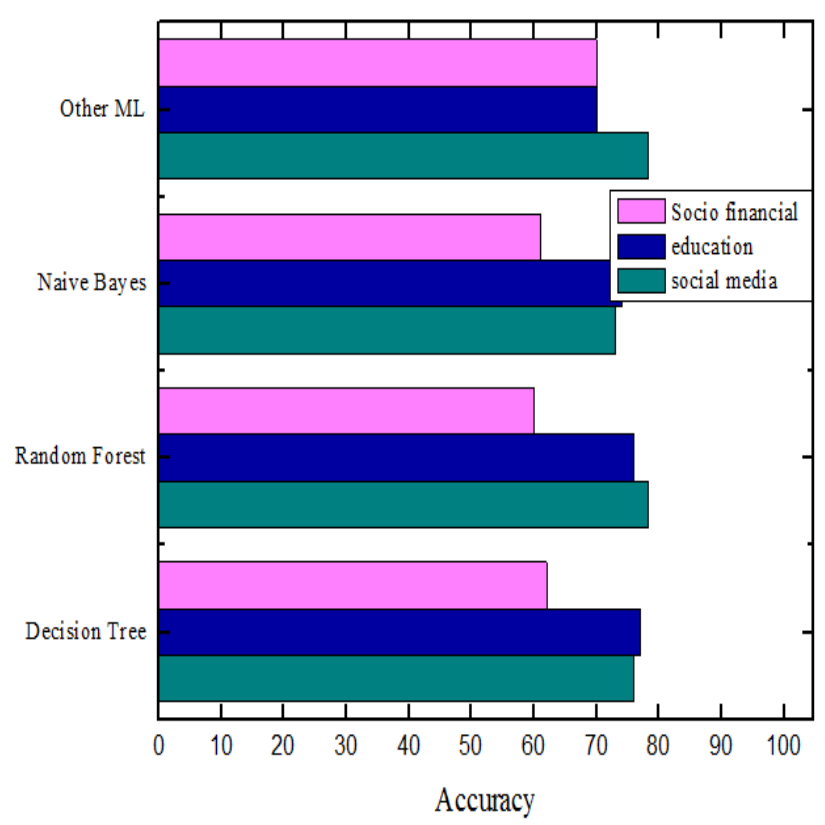

Fig. 6:- The accuracy of e-governance application using various methods

The accuracy of e-governance application using various methods is validated in Fig.6 and table.3. From the graph and table shows that the conventional data mining techniques in e-governance plays a necessary improvement in term of its performance metric accuracy.

\begin{tabular}{|c|c|c|c|}
\hline $\begin{array}{c}\text { Methods and } \\
\text { applications }\end{array}$ & $\begin{array}{c}\text { Social } \\
\text { Media }\end{array}$ & $\begin{array}{c}\text { Educati } \\
\text { on }\end{array}$ & $\begin{array}{c}\text { Socio } \\
\text { Financial }\end{array}$ \\
\hline Decision Tree & 76 & 77 & 62 \\
\hline Random Forest & 78.3 & 76 & 60 \\
\hline Naive Bayes & 73 & 74 & 61 \\
\hline Other ML & 78.2 & 70 & 70 \\
\hline
\end{tabular}

Table.3:- The validation of different data mining approaches in e-governance applications

Moreover, the F-measure, precision and recall obtained by different methods for e-governance applications are shown in Fig.7. 


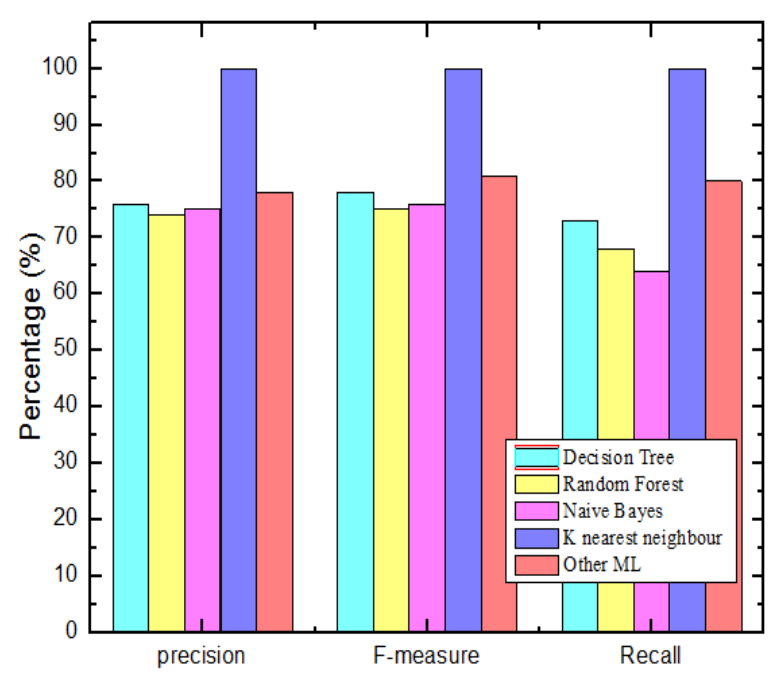

Fig.7:- performance metrics comparisons of various methods

From the validation shows that the k-nearest neighbor method in e-governance application achieved highest precision, more F-measure value and supreme recall. Thus, the overall metrics values observed that the data mining method is a substantial portion in e-governance application for the improved function.

\section{CONCLUSION AND FUTURE WORK}

In this paper, the various the data ware houses as well as data mining execution in e-governance was investigated. Here, the significance of e-governance and its challenges were widely discussed. Moreover, the solution for the egovernance performance was explained. Various types of data warehouse plus data mining approaches used by numerous authors were discussed. From that, the improved e-governance performance in education was validated to the literacy people along with the illiteracy rate. Furthermore, the performance of data mining in some e-governance application was validated. In future, a hybrid method is required to be accepted for improving interoperability between the applications of e-governance that will include the central strategies for file management, complaint management, knowledge management and among others. Moreover, the e-governance creativities in urban/rural areas should be considered using analyzes and recognize popular authenticities

\section{REFERENCES}

[1]. Abreu, Joana Covelo, and Alessandra Silveira. "Interoperability solutions under Digital Single Market: European e-Justice rethought under eGovernance paradigm." European Journal of Law and Technology 9.1 (2018).

[2]. Alhawawsha, Mohammad, and Taras Panchenko. "Open Data Platform Architecture and Its Advantages for an Open E-Government." International Conference on Computer Science, Engineering and Education Applications. Springer, Cham, 2020.
[3]. Alkashri, Zainab, et al. "Mining Dubai Government Tweets to Analyze Citizens' Engagement." Recent Advances in Intelligent Systems and Smart Applications. Springer, Cham 615-638.

[4]. Alkawsi, Gamal Abdulnaser, et al. "A hybrid SEMneural network method for identifying acceptance factors of the smart meters in Malaysia: Challenges perspective." Alexandria Engineering Journal (2020).

[5]. Alkraiji, Abdullah Ibrahim. "Top Management's Role in Promoting Decision Support Systems Efficiency: An Exploratory Study in Government Sector in Saudi Arabia." Journal of Cases on Information Technology (JCIT) 22.1 (2020): 38-56.nd it's Implementation in EGovernance." International Journal of Advanced Research in Computer Engineering \& Technology (IJARCET) 4.8 (2015).

[6]. Allen, Barbara Ann, et al. "E-Governance \& government on-line in Canada: Partnerships, people \& prospects." Government Information Quarterly 18.2 (2001): 93-104.

[7]. Al-Mushayt, Omar Saeed. "Automating EGovernment services with artificial intelligence." IEEE Access 7 (2019): 146821-146829.

[8]. Böhnlein, Michael, and Achim Ulbrich-vom Ende. "Business process oriented development of data warehouse structures." Data Warehousing 2000. Physica, Heidelberg, 2000. 3-21.

[9]. Botchway, Edward Ayebeng, Ezer Osei YeboahBoateng, and Titus Ebenezer Kwofie. "Benefits of egovernance implementation in physical infrastructure development at the local government level." Electronic Government, An International Journal 12.4 (2016): 395-405.

[10]. Chakiri, Houda, Mohammed El Mohajir, and Nasser Assem. "A data warehouse hybrid design framework using domain ontologies for local good-governance assessment." Transforming Government: People, Process and Policy (2020).

[11]. Chakravartty, Paula. "Communication rights and neoliberal development: Technopolitics in India." Communication Rights and Social Justice. Palgrave Macmillan, London, 2014. 269-287.

[12]. Chamikara, Mahawaga Arachchige Pathum, et al. "Efficient privacy preservation of big data for accurate data mining." Information Sciences 527 (2020): 420443.

[13]. Chauhan, Radha. "National e-governance Plan in India." United Nations University-International Institute for Software Technology (2009).

[14]. Coe, Amanda, Gilles Paquet, and Jeffrey Roy. "Egovernance and smart communities: a social learning challenge." Social science computer review 19.1 (2001): 80-93.

[15]. Coman, Marius. "Business Intelligence and Egovernance." LESIJ-Lex ET Scientia International Journal 16.1 (2009): 484-491.

[16]. Dash, Satyabrata, and Subhendu Kumar Pani. "EGovernance paradigm using cloud infrastructure: benefits and challenges." Procedia Computer Science 85 (2016): 843-855. 
[17]. Dawes, Sharon S. "The evolution and continuing challenges of e-governance." Public Administration Review 68 (2008): S86-S102.

[18]. DESAI, DR. "Implementation of Artificial Neural Network Data Mining Algorithm: A Case Study of Birth Registration Data." International Journal of Computer Engineering and Technology 10.1 (2019).

[19]. Giri, Shailendra, Subarna Shakya, and Rose Nath Pande. "E-Governance implementation: challenges of effective service delivery in civil service of Nepal." Global Journal of Computer Science and Technology (2018).

[20]. Govinda, R., and Madhumita Bandyopadhyay. "Decentralization of educational governance in India: Trends and issues." Educational Decentralization. Springer, Dordrecht, 2006. 159-176.

[21]. Gupta, Kriti Priya, Swati Singh, and Preeti Bhaskar. "Citizens' perceptions on benefits of e-governance services." International Journal of Electronic Governance 10.1 (2018): 24-55.

[22]. Gupta, M. P. "Tracking the evolution of e-governance in India." Technology Enabled Transformation of the Public Sector: Advances in E-Government. IGI Global, 2012. 46-58.

[23]. Gupta, Parul Jain, and Pradeep Suri. "Measuring public value of e-governance projects in India: citizens' perspective." Transforming Government: People, Process and Policy (2017).

[24]. Gupta, Piyush, and A. Sridevi. "e-Governance Approach in India The National e-Governance PlanNeGP." Compendium of eGovernance Initiatives in India (2008): 8-23.

[25]. Hanumanthappa, M., B. R. Prakash, and Manish Kumar. "Applications of data mining in e-governance: a case study of bhoomi project." International Conference on Data Engineering and Management. Springer, Berlin, Heidelberg, 2010.

[26]. Haque, M. Shamsul. "E-governance in India: Its impacts on relations amongcitizens, politicians and public servants." International Review of Administrative Sciences 68.2 (2002): 231-250.

[27]. Hasić, Faruk, and Jan Vanthienen. "From decision knowledge to e-government expert systems: the case of income taxation for foreign artists in Belgium." Knowledge and Information Systems 62.5 (2020): 2011-2028.

[28]. Jayashree, G., and C. Priya. "Comprehensive Guide to Implementation of Data Warehouse in Education." Intelligent Computing and Innovation on Data Science. Springer, Singapore, 2020. 1-8.

[29]. Kalsi, N. S., Ravi Kiran, and S. C. Vaidya. "Effective e-governance for good governance in India." International Review of Business Research Papers 5.1 (2009): 212-229.

[30]. Kern, Rafał, Adrianna Kozierkiewicz, and Marcin Pietranik. "The data richness estimation framework for federated data warehouse integration." Information Sciences 513 (2020): 397-411.

[31]. Khan, Naheed, et al. "Strengthening e-Education in India using Machine Learning." Available at SSRN 3565255 (2020).
[32]. Khot, Smita, et al. "Big Data Mining approach to Egovernance: Mining Census data for enhanced citizen centric policy making." International Journal of Engineering and Computer Science 6.12 (2017): 22312-22314.

[33]. Kim, Gang-Hoon, Silvana Trimi, and Ji-Hyong Chung. "Big-data applications in the government sector." Communications of the ACM 57.3 (2014): 7885.

[34]. Kondeti, Phani Krishna, et al. "Applications of machine learning techniques to predict filariasis using socio-economic factors." Epidemiology \& Infection 147 (2019).

[35]. Kum, Hye-Chung, Dean F. Duncan, and C. Joy Stewart. "Supporting self-evaluation in local government via Knowledge Discovery and Data mining." Government Information Quarterly 26.2 (2009): 295-304.

[36]. Lee, Taejun, Byung-Kwan Lee, and Seulki LeeGeiller. "The effects of information literacy on trust in government websites: Evidence from an online experiment." International Journal of Information Management 52 (2020): 102098.

[37]. Liu, Luning, Jingrui Ju, and Yuqiang Feng. "An extensible framework for collaborative e-governance platform workflow modeling using data flow analysis." Information Technology for Development 23.3 (2017): 415-437.

[38]. Liu, Qi, et al. "Managing Data Quality of the Data Warehouse: A Chance-Constrained Programming Approach." Information Systems Frontiers (2019): 115.

[39]. Madon, Shirin. "Evaluating the developmental impact of e-governance initiatives: An exploratory framework." The Electronic Journal of Information Systems in Developing Countries 20.1 (2004): 1-13.

[40]. Malhotra, Harmeet, Meenu Dave, and Tripti Lamba. "Security Analysis of Cyber Attacks Using Machine Learning Algorithms in eGovernance Projects." International Conference on Futuristic Trends in Networks and Computing Technologies. Springer, Singapore, 2019.

[41]. Mazzarella, William. "Internet X-ray: e-governance, transparency, and the politics of immediation in India." Public Culture 18.3 (2006): 473-505.

[42]. Misuraca, Gianluca, and Gianluigi Viscusi. "Is open data enough?: E-governance challenges for open government." International Journal of Electronic Government Research (IJEGR) 10.1 (2014): 18-34.

[43]. Mukherjee, Falguni. "GIS use by an urban local body as part of e-governance in India." Cartography and Geographic Information Science 45.6 (2018): 556-569.

[44]. Nagaraja, K. "E-Governance in India: Issues and Challenges." IOSR Journal of Economics and (2016).

[45]. Navdeep, Preet, Manish Arora, and Neeraj Sharma. "Role of big data analytics in analyzing e-Governance projects." New trends in business and management: An international perspective (2016). 
[46]. Oliveira, Thays A., Miquel Oliver, and Helena Ramalhinho. "Challenges for Connecting Citizens and Smart Cities: ICT, E-Governance and Blockchain." Sustainability 12.7 (2020): 2926.

[47]. Panganiban, Gerald Glenn F. "E-governance in agriculture: digital tools enabling Filipino farmers." Journal of Asian Public Policy 12.1 (2019): 51-70.

[48]. Panwar, Arvind, and Vishal Bhatnagar. "Scrutinize the Idea of Hadoop-Based Data Lake for Big Data Storage." Applications of Machine Learning. Springer, Singapore, 2020. 365-391.

[49]. Pappel, Ingrid, Valentyna Tsap, and Dirk Draheim. "The e-LocGov Model for Introducing e-Governance into Local Governments: an Estonian Case Study." IEEE Transactions on Emerging Topics in Computing (2019).

[50]. Patnaik, Pabitrananda, and Subhashree Pattnaik. "Impact of Decision Science on e-Governance: A Study on Odisha Land Records System." New Paradigm in Decision Science and Management. Springer, Singapore, 2020. 151-164.

[51]. Patnaik, Pabitrananda, Subhashree Pattnaik, and Pratibha Singh. "Use of Data Analytics for Effective E-Governance: A Case Study of "EMutation" System of Odisha." Advances in Data Science and Management. Springer, Singapore, 2020. 109-122.

[52]. Riley, Cathia Gilbert. "The Changing Role of the Citizen in the E-governance and E-democracy equation." Commonwealth centre for egovernance (2003).

[53]. Sangeetha, G., and L. Manjunatha Rao. "Modelling of E-governance framework for mining knowledge from massive grievance redressal data." International Journal of Electrical and Computer Engineering 6.1 (2016): 367.

[54]. Saxena, Kul Bhushan Chandra. "Towards excellence in e-governance." International Journal of Public Sector Management (2005).

[55]. Shah, Mrinalini. "E-governance in India: Dream or reality." International Journal of Education and Development using ICT 3.2 (2007).

[56]. Shukla, Parag Sunil, and Mayank Mathur. "Conceptualizing the Role of Data Analytics and Technology in E-Governance: An Insight." International Journal of Business Analytics (IJBAN) 7.2 (2020): 1-12.

[57]. Singh, Amit Kumar, and Chandan Kumar. "Encryption-Then-Compression-Based Copyright Protection Scheme for E-Governance." IT Professional 22.2 (2020): 45-52.

[58]. Singh, Gurmeet, et al. "E-governance for improved public sector service delivery in India, Ethiopia and Fiji." International Journal of Public Sector Management (2010).

[59]. Sivani, K. M. S. "Critical Analysis of the Effects of Regulations under Competition Law on Mergers and Acquisitions: A Comparison of the India, EU, US and UK Laws." Journal of Corporate Governance \& International Business Law 2.2 (2020).
[60]. Siyam, Nur, Omar Alqaryouti, and Sherief Abdallah. "Mining government tweets to identify and predict citizens engagement." Technology in Society 60 (2020): 101211.

[61]. Solihin, Wawan, et al. "Simplified schema queries for supporting BIM-based rule-checking applications." Automation in Construction 117 (2020): 103248.

[62]. Suri, P. K. "Measuring E-Governance Performance." Strategic Planning and Implementation of E-Governance. Springer, Singapore, 2017. 25-39.

[63]. Syarafah, Shabrina Habi, and Setyo Riyanto. "EGovernment Strategy as the Implementation of Good Corporate Governance in the Ministry of Public Works and Public Housing."

[64]. Thomas, Pradip. "Bhoomi, Gyan Ganga, e-governance and the right to information: ICTs and development in India." Telematics and Informatics 26.1 (2009): 20-31.

[65]. Tirpude, Shubhangi, Aarti Karandikar, and Rashmi Welekar. "An Approach for Environment Vitiation Analysis and Prediction Using Data Mining and Business Intelligence." Smart Trends in Computing and Communications. Springer, Singapore, 2020. 327338.

[66]. Verma, Krishna Kumar, and Navita Shrivastava. "Exploring Role and Associated Challenges of Data Mining Technique and it's Implementation in EGovernance." International Journal of Advanced Research in Computer Engineering \& Technology (IJARCET) 4.8 (2015).

[67]. Wadhwa, Manisha. "e-Governance in healthcare sector in India." (2020).

[68]. Wang, Chen-Shu, et al. "An integrated data analytics process to optimize data governance of non-profit organization." Computers in Human Behavior 101 (2019): 495-505.

[69]. Worku, Kiflie, and Filmon Hadaro. "ICT as Policy Fashion or Really it Worth in Public Sectors to Ensure Good Governance?." Journal of Business and economics 1.2 (2019): 292-313.

[70]. Zhang, Nan, Xuejiao Zhao, and Xiaopei He. "Understanding the relationships between information architectures and business models: An empirical study on the success configurations of smart communities." Government Quarterly 37.2 (2020): 101439. 